\title{
Not All Patients with a Pancreatic Neuroendocrine Tumour Will Benefit from All Approved or Recommended Therapeutic Options: A Real-Life Retrospective Study
}

\author{
Amandine Berdelou $^{a} \quad$ Valérie Boige $^{b} \quad$ Julia Arfi-Rouche ${ }^{c}$ David Malkab \\ Stéphane Ederhy ${ }^{d}$ Hassan Izzedine ${ }^{e}$ Sophie Leboulleux ${ }^{a} \quad$ Cécile N. Chougnet $^{a}$ \\ Pascal Burtin $^{b}$ Thierry De Baere ${ }^{f}$ Agnès Laplancheg Dominique Elias $^{\text {h }}$ \\ Martin Schlumberger ${ }^{a} \quad$ Jean-Yves Scoazec ${ }^{i}$ Michel Ducreux $^{b}$ Eric Baudin ${ }^{a}$ \\ Departments of ${ }^{a}$ Nuclear Medicine and Endocrine Tumours, ${ }^{b}$ Gastrointestinal Oncology and ${ }^{c}$ Radiology, Gustave \\ Roussy, Université Paris XI, Villejuif, ${ }^{d}$ Department of Cardiology, Saint Antoine Hospital, and ${ }^{e}$ Department of \\ Nephrology, Pitié Salpêtrière Hospital, Paris, and Departments of ${ }^{f}$ Image-Guided Therapy, ${ }^{9}$ Biostatistics and

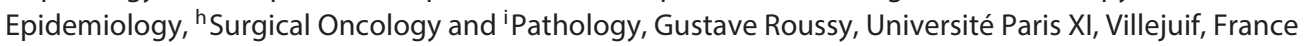

\section{Key Words}

Safety · Neuroendocrine tumour · Pancreatic tumour .

Therapeutic lines

\begin{abstract}
Background: At least nine therapeutic options are recommended or approved for pancreatic neuroendocrine tumour (pNET). The primary endpoint of this study was to determine the number of therapeutic lines given before death. Secondary endpoints were to determine toxic events as a function of number of therapeutic lines and of time. Methods: Patients with pNET treated between 1998 and 2010 at our centre were characterised. All therapeutic lines were recorded as well as tumour- or toxic-related deaths. Persistent treatment-related toxicity (PTRT) was defined as: chronic kidney disease, anaemia, thrombocytopenia, neutropenia, severe liver failure, cardiac failure and recurrent sepsis, precluding at least one other therapeutic option or second cancers. $\boldsymbol{R e}$ sults: Ninety-two patients were analysed. The median follow-up was 7 years. The 1-, 2- and 5-year overall survival rates
\end{abstract}

\section{KARGER}

(C) 2016 S. Karger AG, Basel

E-Mail karger@karger.com

www.karger.com/nen were 90,81 and 51\%, respectively. After 3 and 5 therapeutic lines, 23 and $50 \%$ of patients had died, respectively. After 3 and 5 lines, the frequency of toxic events was 8 and 24\%, respectively. Overall, 17 toxic events were observed including 6 treatment-related deaths and 11 PTRT. After 1, 2 and 5 years of treatment, the frequency of toxic events was 6,9 and $16 \%$, respectively. Conclusion: Tumour- and toxic-related deaths as well as PTRT may preclude access to all therapeutic options in patients with pNET. Optimised risk benefit sequence should be investigated.

(c) 2016 S. Karger AG, Basel

\section{Introduction}

Pancreatic neuroendocrine tumours ( $\mathrm{pNET}$ ) represent less than $5 \%$ of neuroendocrine tumours, and more than $50 \%$ of patients present with metastases at the time of diagnosis $[1,2]$.

The therapeutic management of metastatic pNET aims to control both the functioning status of the tumour and

Eric Baudin

Department of Nuclear Medicine and Endocrine Tumours Gustave Roussy, 114 rue Edouard Vaillant

FR-94800 Villejuif (France)

E-Mail eric.baudin@gustaveroussy.fr 
its growth. In the absence of cure and due to the prolonged survival of subgroups of patients with metastatic pNET, striking a balance between the risks and benefits of therapy is a constant concern for physicians. The historical therapeutic management of metastatic pNET comprises the use of surgery, imaging-guided locoregional therapies, streptozotocin-based chemotherapy and interferon [3-7]. More recently, following the results of retrospective studies, the use of temozolomide- or oxaliplatin-based chemotherapies has increased the number of therapeutic options [8-10]. In addition, peptide receptor radionuclide therapy (PRRT) has emerged as an option based on phase I-II trials and compassionate studies $[11,12]$. Also, three positive placebo-controlled phase III trials have recently been published in pNET patients leading to the approval of three targeted therapies: sunitinib, everolimus and lanreotide [13-15]. Finally, treatment combinations are now emerging [16]. At present, patients may benefit from a long list of available therapeutic options, at least nine for patients suffering from metastatic pNET [17], and the question of the best strategy is now open for discussion.

To achieve progress in this field, one unanswered but critical question is the number of lines that patients with pNET could be administered before tumour-related death occurs. In addition, toxicity-related deaths but also the rate of persistent treatment-related toxicity (PTRT) may also affect the feasibility of sequential therapies and should also be known as well as the parameters that affect the safety of the respective treatments. Not only prospective trials with sequential design are necessary to solve this issue but also retrospective studies which provide long-term follow-up observation throughout the therapeutic management [18].

The primary endpoint of this retrospective study was to determine the number of therapeutic lines given before tumour- or toxicity-related death in patients treated for metastatic pNET in a single centre of expertise. Secondary endpoints were to determine toxic events defined as PTRT for more than 3 months or treatment-related death as a function of number of therapeutic lines and of time. Finally, in a preliminary exploratory analysis, we looked for the relationship between baseline characteristics and the presence of toxic events at any times.

\section{Patients and Methods}

\section{Population}

This retrospective study reviewed consecutive patients with metastatic unresectable pNET followed up in our institution between May 1998 and December 2010. Inclusion criteria were:

History of Therapeutic Intervention in pNET
Table 1. Patient and tumour characteristic

\begin{tabular}{|c|c|}
\hline & Patients $(\mathrm{n}=92)$ \\
\hline Median age [range], years & $55[22-78]$ \\
\hline Male/female ratio & $45 / 47$ \\
\hline Functional syndromes & $31(34)^{\mathrm{a}}$ \\
\hline \multicolumn{2}{|l|}{ Genetic status } \\
\hline Sporadic & $88(96)$ \\
\hline MEN1 & $3(3)$ \\
\hline NF1 & $1(1)$ \\
\hline \multicolumn{2}{|l|}{ Chromogranin A } \\
\hline Unknown & $18(20)$ \\
\hline Normal & $18(20)$ \\
\hline \multicolumn{2}{|l|}{ Elevated } \\
\hline$>1-5 \mathrm{UNL}$ & $25(27)$ \\
\hline$\geq 5-10 \mathrm{UNL}$ & $12(13)$ \\
\hline$\geq 10$ UNL & $19(20)$ \\
\hline \multicolumn{2}{|l|}{ ENETS grade } \\
\hline Unknown & $19(21)$ \\
\hline 1 & $29(32)$ \\
\hline 2 & $38(41)$ \\
\hline 3 & $6(6)$ \\
\hline \multicolumn{2}{|l|}{ Ki67 } \\
\hline Unknown & $23(25)$ \\
\hline$\leq 2$ & $32(35)$ \\
\hline $3-20$ & $32(35)$ \\
\hline$>20$ & $5(5)$ \\
\hline \multicolumn{2}{|l|}{ Mitoses } \\
\hline Unknown & $31(34)$ \\
\hline$<2$ & $36(39)$ \\
\hline $2-20$ & $24(26)$ \\
\hline$>20$ & $1(1)$ \\
\hline Median primary tumour size [range], $\mathrm{mm}$ & $55[18-200]$ \\
\hline \multicolumn{2}{|l|}{ Somatostatin receptor scintigraphy } \\
\hline Unknown & $22(24)$ \\
\hline Positive & $61(66)$ \\
\hline Negative & $9(10)$ \\
\hline Metastatic organs [range] & $1[0-4]$ \\
\hline \multicolumn{2}{|l|}{ ENETS staging } \\
\hline Stage III & $4(4)$ \\
\hline Stage IV & $88(96)$ \\
\hline \multicolumn{2}{|l|}{ Liver involvement } \\
\hline Uncertain & $26(28)$ \\
\hline$\leq 30 \%$ & $35(38)$ \\
\hline $30-70 \%$ & $19(21)$ \\
\hline$\geq 70 \%$ & $12(13)$ \\
\hline \multicolumn{2}{|l|}{ Patients treated } \\
\hline Before 2006 & $45(49)$ \\
\hline From 2006 onward & $47(51)$ \\
\hline
\end{tabular}

Values are presented as $\mathrm{n}(\%)$, unless otherwise indicated. MEN1 = Multiple endocrine neoplasia type $1 ; \mathrm{NF} 1=$ neurofibromatosis type 1 ; UNL $=$ upper limit of normal. ${ }^{\text {a }} 31$ functioning syndromes including 4 gastrin-, 1 GHRH (growth hormone-releasing syndrome)-, 7 serotonin-, 3 somatostatin-, 2 PTHRP (parathyroid hormone-related protein)-, 6 glucagon-, 1 VIP (vasoactive intestinal peptide)-, 6 insulin- and 1 ACTH (adrenocorticotropic hormone)-dependent. 
(1) reviewed well-differentiated architecture of NET based on biopsy or surgical specimens by one single pathologist, (2) TNM stage IV or unresectable stage III disease as defined by both scintigraphic and conventional imaging, and (3) at least one therapeutic line. Exclusion criteria were: (1) the lack of follow-up and (2) poorly differentiated neuroendocrine carcinoma.

The following parameters were recorded for all patients at the time of the first therapeutic intervention: age, gender, comorbidity (tobacco use, hypertension, dyslipidaemia, diabetes mellitus, obesity), routine biological tests before treatment (glycaemia, creatinine, ASAT, ALAT, bilirubin, haemoglobin, platelet, neutrophil counts), chromogranin A levels, inherited syndromes, functioning status, liver tumour involvement, number of invaded organs based on computed tomography and/or magnetic resonance imaging, grading as defined by the $2010 \mathrm{WHO}$ classification, somatostatin receptor scintigraphy status, and the type and number of therapeutic lines.

\section{Treatment}

The following systemic therapeutic options were given and were considered as one therapeutic line: somatostatin analogues (SSA), interferon, sunitinib, everolimus, PRRT, dacarbazine, streptozotocin, 5-fluorouracil (5FU) or platin-based chemotherapies [3, 4, 6-8, $12,15,19]$. In addition, transhepatic arterial chemoembolization (TACE) was also considered as a therapeutic line. Treatments were given according to recommendations and/or the main publications in the field and discussed within the setting of a multidisciplinary meeting for more than 20 years. The main characteristics of our strategy have previously been described [4, 16, 20-22].

\section{Safety}

Safety was recorded retrospectively according to National Cancer Institute (NCI) common terminology criteria for adverse events version 4 (CTCAE v4.0) during the follow-up. Drug-related toxic events were specifically analysed and defined as a lethal toxicity (grade 5) or as persistent treatment-related (grade 2-4) toxicity lasting more than 3 months (PTRT) after the last treatment administration which precluded at least one subsequent therapeutic line. PTRT included chronic kidney disease (estimated glomerular filtration rate $<60 \mathrm{ml} / \mathrm{min} / 1.73 \mathrm{~m}^{2}$ ), anaemia (haemoglobin $<8 \mathrm{~g} / \mathrm{dl})$, thrombocytopenia $\left(<100,000 / \mathrm{mm}^{3}\right)$, neutropenia $\left(<1,500 / \mathrm{mm}^{3}\right)$, jaundice (bilirubinaemia $\left.>50 \mu \mathrm{M}\right)$, severe liver failure (prothrombin time $<50 \%$ ), cardiac toxicities [left ventricular systolic dysfunction: left ventricular ejection fraction (LVEF) $<50 \%$, heart failure], recurrent sepsis and second cancer. Toxic events were classified according to the type of organ: liver, renal, cardiac, haematological and infectious toxicities. Pretreatment echocardiography was routinely performed when cardiac toxicity was expected [23].

\section{Statistical Analysis}

The primary endpoint of this retrospective study was to determine the number of therapeutic lines given before tumour- or toxicity-related death in a population with advanced pNET. The baseline time was when the first line was initiated. The number of therapeutic lines was calculated from the date of the first line to the date of first PTRT or to the date of toxic- or tumour-related death or to the last date of follow-up.

The secondary endpoints were to determine toxic events defined as PTRT or related to death after 2, 3 and 5 therapeutic lines
Table 2. Type of therapeutic lines according to the line of treatment

\begin{tabular}{lccc}
\hline Therapeutic lines & $\begin{array}{c}\text { First line } \\
(\mathrm{n}=92)\end{array}$ & $\begin{array}{l}\text { Second line } \\
(\mathrm{n}=87)\end{array}$ & $\begin{array}{c}\text { All lines } \\
(\mathrm{n}=92)\end{array}$ \\
\hline SSA & $23(25)$ & $10(11)$ & $47(51)$ \\
Interferon & $1(1)$ & $0(0)$ & $1(1)$ \\
TACE & $10(11)$ & $15(17)$ & $43(47)$ \\
Dacarbazine-based CT & $0(0)$ & $0(0)$ & $18(20)$ \\
Streptozotocin-based CT & $32(35)$ & $33(38)^{\mathrm{a}}$ & $64(70)$ \\
Platin-based CT & $20(22)$ & $13(15)$ & $53(57)$ \\
$\quad$ Oxaliplatin-based & $6(6)$ & $10(11)$ & $36(39)$ \\
$\quad$ Cisplatin or carboplatin-based & $14(15)$ & $3(3)$ & $17(18)$ \\
Fluorouracil-based CT & $3(3)$ & $3(3)^{\mathrm{b}}$ & $15(16)$ \\
PRRT & $2(2)$ & $2(2)$ & $26(28)$ \\
Sunitinib & $0(0)$ & $3(3)$ & $24(26)$ \\
Everolimus & $1(1)$ & $8(9)$ & $40(44)$
\end{tabular}

Values are shown as $\mathrm{n}(\%)$. CT $=$ Chemotherapy. ${ }^{\text {a Streptozot- }}$ ocin-based chemotherapy + bevacizumab (3 patients) ${ }^{\mathrm{b}} 5 \mathrm{FU}+$ external beam radiotherapy ( 1 patient).

or at 1, 2 and 5 years of treatment. Toxic events and overall survival (OS) were estimated using the Kaplan-Meier method considering the time following the first therapeutic line or the number of lines. Associations between baseline characterization and presence or absence of toxic events at the end of follow-up were analysed with $\chi^{2}$ (with or without Yates correction) or Fisher's exact test. A $p$ value $<0.05$ was considered significant.

\section{Results}

\section{Characteristics of the Population under Study}

Among 146 consecutive patients with pNET referred to our institution between May 1998 and December 2010, 55 patients were excluded due to non-pNET morphology $(n=6)$, a localised intra-pancreatic tumour $(n=18)$, follow-up outside our institution $(\mathrm{n}=27)$, and no systemic treatment initiated $(n=3)$. Finally, a total of 92 pNET patients ( 45 male and 47 female, median age 55 years, range: $22-78$ years) with a diagnosis of unresectable/metastatic pNET were enrolled. The main patient characteristics are described in table 1. Forty-seven out of 92 patients were treated from 2006 onward at a time when all therapeutic options became available.

\section{Description of Therapeutic Lines}

Among 92 patients, the most frequent first therapeutic line was systemic chemotherapy given in $55(60 \%)$ patients. Twenty-three patients (25\%) received SSA, and 10 (11\%) patients were treated with TACE as first-line therapy (table 2).
Berdelou et al. 


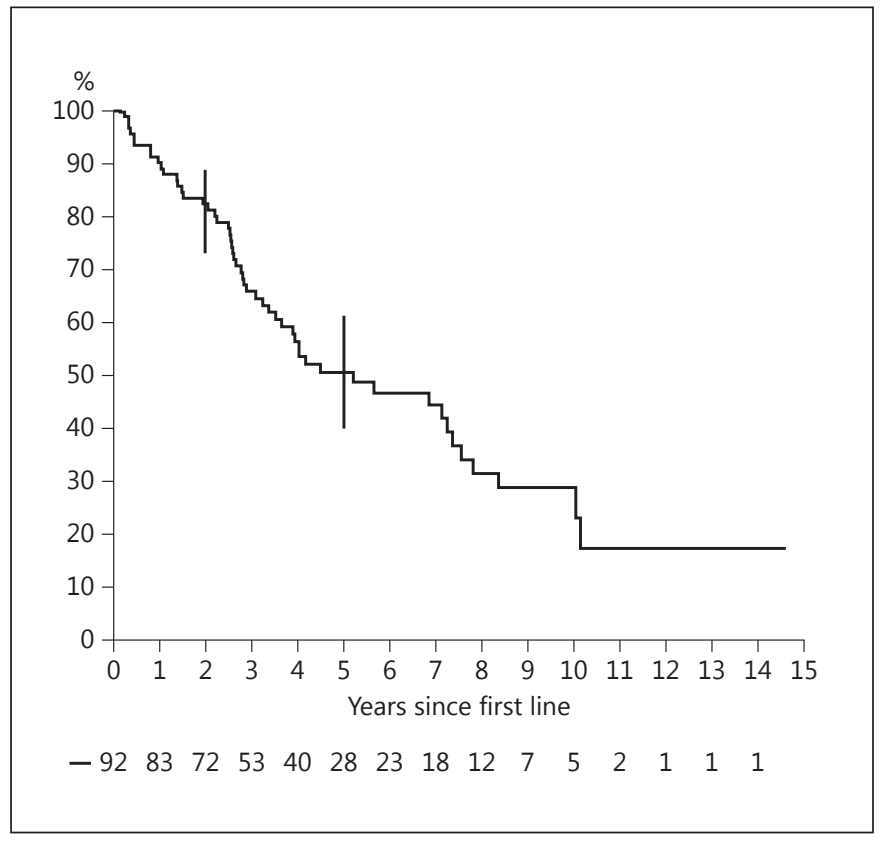

Fig. 1. OS in 92 patients with metastatic or unresectable pNET as a function of time since the first line.

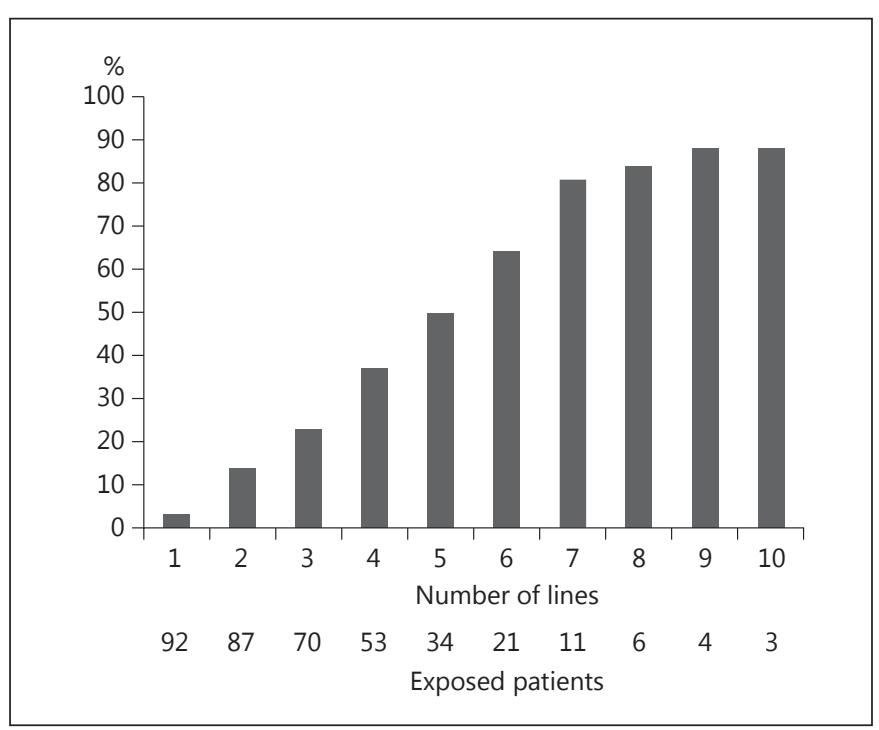

Fig. 2. Percentage of death in 92 patients with metastatic or unresectable pNET as a function of the number of therapeutic lines.

During the course of the disease, nearly half of the population received SSA (51\%), TACE (47\%) or everolimus (44\%). A quarter of the patients received PRRT (28\%) or sunitinib (26\%). Streptozotocin-, platin-, dacarbazineand/or fluorouracil-based chemotherapies were given in

History of Therapeutic Intervention in pNET

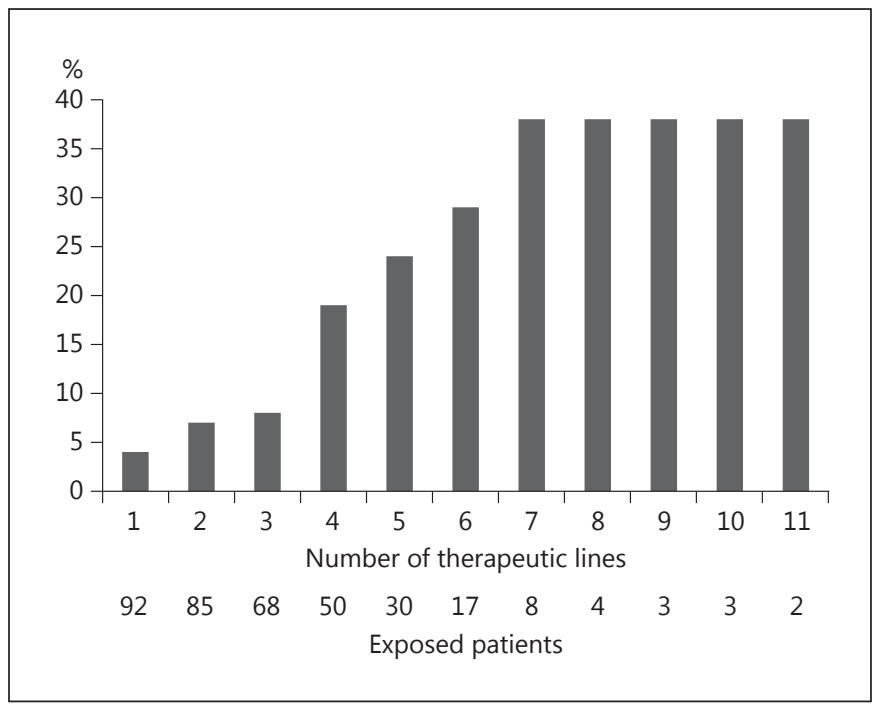

Fig. 3. Frequency of toxic events as a function of the number of therapeutic lines.

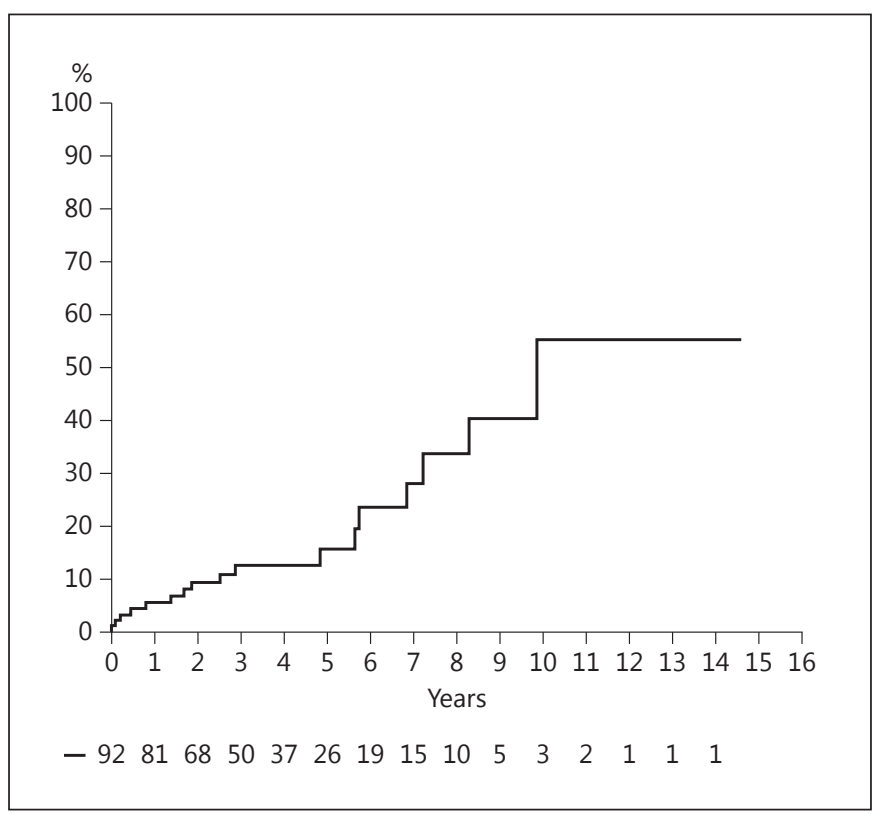

Fig. 4. Frequency of toxic events as a function of time (years).

$64(70 \%), 53(57 \%), 18(20 \%)$ and $15(16 \%)$ cases, respectively. Among platin-based chemotherapies, $36(39 \%)$ and $17(18 \%)$ patients received oxaliplatin- and cisplatinbased chemotherapy during the course of the study or, as first line, in $6(6 \%)$ or 14 (15\%) cases, respectively (table 2).

Neuroendocrinology 2017;105:26-34 DOI: $10.1159 / 000446988$ 
Fig. 5. Toxic events according to organ: number of patients with a toxic event as a function of the type of toxic event. In each column, the number of treatment-related deaths is indicated in dark grey and the number of treatment-related toxicity without death is indicated in light grey.

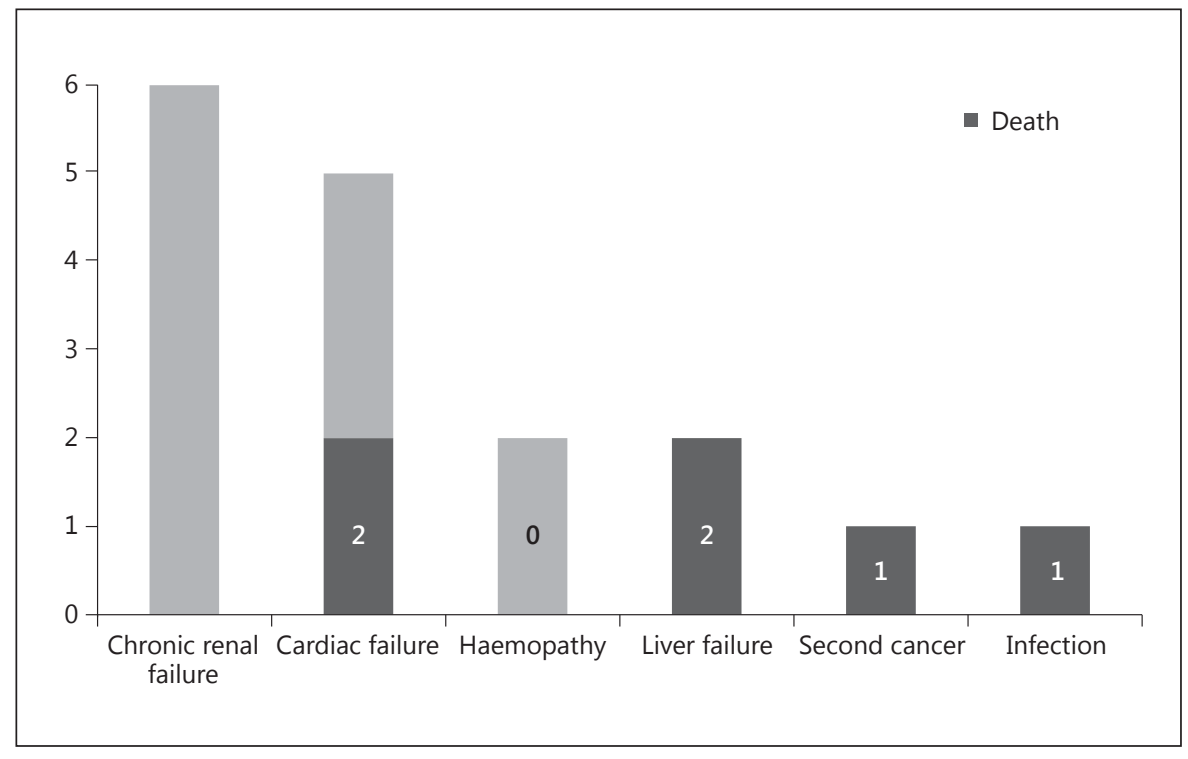

OS as a Function of the Number of Therapeutic Lines

After a median follow-up of 79 months, 52 patients had died. The median OS was 5 years. The 1-, 2- and 5 -year OS rates were 90\% (95\% CI: 82-95), 81\% (95\% CI: 72-88) and 51\% (95\% CI: 40-61), respectively (fig. 1). Deaths were classified as tumour- or treatment-related, others and unknown in 35 (67\% of dead patients), 6 (12\%), 4 (8\%) and 7 (13\%) cases, respectively. The causes of treatment-related deaths were as follows: cardiac failure $(\mathrm{n}=2)$, liver failure $(\mathrm{n}=2)$, infection $(\mathrm{n}=1)$ and second cancer $(\mathrm{n}=1)$. After 2, 3, 4 and 5 therapeutic lines, $15,23,38$ and $50 \%$ of patients had died (fig. 2).

\section{Toxic Events}

Toxic events were observed in 17/92 patients (18\%). Among the 17 toxic events, 6 treatment-related deaths (35\%) and 11 permanent toxicities (65\%) occurred. After $1,2,3,4$ and 5 lines, the frequency of toxic events was 4 , $7,8,19$ and $24 \%$, respectively (fig. 3). One, 2 and 5 years after the first-line treatment, the frequency of toxic events was 6, 9 and 16\%, respectively (fig. 4).

The classification of toxic events by organ was as follows: nephrotoxicity ( 6 patients, no death), cardiac toxicity ( 5 patients including 2 treatment-related deaths), haematological malignancy (2 patients, no death), fatal liver failure ( 2 patients), fatal second cancer (1 patient) and fatal infection (1 patient) (fig. 5).

Renal and cardiac toxicities are detailed in table 3. Concerning nephrotoxicity, 5 patients experienced grade $2(\mathrm{n}=4)$ and grade $3(\mathrm{n}=1)$ chronic kidney disease and
1 patient experienced haemolytic uremic syndrome with renal insufficiency. None of these toxicities were lethal. Concerning cardiac toxicity, 2 patients died of cardiac toxicity including acute heart failure with QT prolongation $(\mathrm{n}=1)$ and acute coronary syndrome after a $5 \mathrm{FU}$ infusion followed by left ventricular systolic dysfunction $(n=1)$. Three patients experienced grade 3 or 4 heart failure related to left ventricular systolic dysfunction. Toxic therapeutic sequences are described in table 3.

The median duration of follow-up was 83 and 69 months for patients who experienced toxic events and for those who did not, respectively; therefore, more patients treated before 2006 experienced toxic events. In a preliminary analysis, we attempted to correlate the baseline tumour and patient characteristics with the onset of toxic events. No significant relationship was found between baseline characteristics of the patients and tumours including functioning status, liver involvement or number of metastatic organs. A trend was found for more frequent toxic events in patients with Ki67 >10\%: 31\% of patients with toxic events. Age $>55$ years was significantly more frequent in patients with toxic events (table 4 ).

\section{Discussion}

Our study aimed to answer the following pragmatic question: how often are pNET patients able to receive all available therapeutic options? Indeed, the therapeutic landscape of advanced pNET patients has recently been 
Table 3. Detailed characteristics of patients with renal and cardiac toxicities

\begin{tabular}{|c|c|c|c|c|c|c|}
\hline Sex & $\begin{array}{l}\text { Age, } \\
\text { years }\end{array}$ & Comorbidities & $\begin{array}{l}\text { Systemic therapeutic } \\
\text { lines }\end{array}$ & Local therapy & Organ toxicity & $\begin{array}{l}\text { Cause of } \\
\text { toxicity- } \\
\text { related death }\end{array}$ \\
\hline $\mathrm{F}$ & 58 & Diabetes & $\begin{array}{l}\text { DS, SSA, 5FUS, } \\
\text { everolimus }\end{array}$ & Cementoplasty (bone) & $\begin{array}{l}\text { Nephrotoxicity, } \\
\text { CKD grade } 2\end{array}$ & - \\
\hline$\overline{\mathrm{M}}$ & 60 & $\begin{array}{l}\text { Tobacco use, hypertension, } \\
\text { diabetes, prostate carcinoma }\end{array}$ & $\begin{array}{l}\text { GEMOX, CDDP, 5FU, } \\
\text { FOLFOX, PRRT, } \\
\text { sunitinib }\end{array}$ & Distal pancreatectomy & $\begin{array}{l}\text { Nephrotoxicity, } \\
\text { CKD grade } 2\end{array}$ & - \\
\hline $\bar{F}$ & 56 & $\begin{array}{l}\text { Hypertension, dyslipidaemia, } \\
\text { acute coronary syndrome }\end{array}$ & CDDP, SSA & None & $\begin{array}{l}\text { Nephrotoxicity, } \\
\text { CKD grade } 2\end{array}$ & - \\
\hline$\overline{\mathrm{F}}$ & 61 & Hypertension & DS & None & $\begin{array}{l}\text { Nephrotoxicity, } \\
\text { CKD grade } 3\end{array}$ & - \\
\hline$\overline{\mathrm{F}}$ & 66 & Diabetes & $\begin{array}{l}\text { DS, SSA, PRRT, } \\
\text { everolimus, FOLFOX }\end{array}$ & None & $\begin{array}{l}\text { Nephrotoxicity, } \\
\text { CKD grade } 2\end{array}$ & - \\
\hline $\bar{M}$ & 55 & Dyslipidaemia, tobacco use & $\begin{array}{l}\text { SSA, everolimus, } \\
\text { sunitinib }\end{array}$ & $\begin{array}{l}\text { Pancreaticoduodenectomy, } \\
\text { liver radiofrequency ablation, } \\
\text { liver stereotactic radiation } \\
\text { therapy }\end{array}$ & $\begin{array}{l}\text { Nephrotoxicity, } \\
\text { haemolytic and } \\
\text { uremic syndrome, } \\
\text { CKD }\end{array}$ & - \\
\hline $\bar{M}$ & 76 & $\begin{array}{l}\text { Tobacco use, diabetes, } \\
\text { hypertension }\end{array}$ & $\begin{array}{l}\text { SSA, DS }\left(525 \mathrm{mg} / \mathrm{m}^{2}\right) \text {, } \\
\text { 5FUD }\end{array}$ & TACE & $\begin{array}{l}\text { Acute coronary } \\
\text { syndrome }\end{array}$ & $\begin{array}{l}\text { Cardiac } \\
\text { toxicity (not } \\
\text { detailed) }\end{array}$ \\
\hline $\bar{M}$ & 57 & Hypertension, diabetes & SSA, DS & None & $\begin{array}{l}\text { Left ventricular } \\
\text { systolic dysfunction }\end{array}$ & - \\
\hline$\overline{\mathrm{M}}$ & 57 & $\begin{array}{l}\text { Diabetes, dyslipidaemia, } \\
\text { coronary artery bypass graft } \\
\text { surgery }\end{array}$ & $\begin{array}{l}\text { DS }\left(400 \mathrm{mg} / \mathrm{m}^{2}\right), 5 \mathrm{FUS}, \\
\text { SSA, PRRT }\end{array}$ & TACE, distal pancreatectomy & $\begin{array}{l}\text { Left ventricular } \\
\text { systolic dysfunction }\end{array}$ & - \\
\hline $\bar{M}$ & 74 & $\begin{array}{l}\text { Diabetes, dyslipidaemia, } \\
\text { hypertension, aortic valve } \\
\text { disease }\end{array}$ & DS $\left(550 \mathrm{mg} / \mathrm{m}^{2}\right)$ & Distal pancreatectomy & $\begin{array}{l}\text { Heart failure, left } \\
\text { ventricular systolic } \\
\text { dysfunction, } \\
\text { conduction disorders }\end{array}$ & - \\
\hline $\bar{F}$ & 50 & None & DS & TACE (chromogranin A) & $\begin{array}{l}\text { Heart failure, left } \\
\text { ventricular systolic } \\
\text { dysfunction, } \\
\text { conduction disorders }\end{array}$ & Heart failure \\
\hline
\end{tabular}

Regarding treatment options given in patients experiencing toxic events, 6 patients with renal failure received various therapeutic lines including PRRT, streptozotocin- or platin-based chemotherapy, TACE, sunitinib, or everolimus. Otherwise, all the patients with cardiac failure had received doxorubicinbased chemotherapy and TACE. The cumulative dose of doxorubicin-based chemotherapy (systemic and TACE) was below the recommended cumulative dose of $550 \mathrm{mg} / \mathrm{m}^{2}$.

DS = Doxorubicin-streptozotocin; $\mathrm{D}=$ Dacarbazine; $5 \mathrm{FUS}=5$ fluorouracil-streptozotocin GEMOX $=$ oxaliplatin-gemcitabine; FOLFOX $=5$ fluorouraciloxaliplatin; $\mathrm{CDDP}=$ cisplatin-etoposide; $\mathrm{CKD}=$ chronic kidney disease.

diversified $[17,24]$. To the best of our knowledge, this is the first study to describe the history of therapeutic interventions in pNETs in the real-life setting.

Baseline characteristics of the population under study can be considered as representative of an advanced pNET population. Even if the vast majority of the systemic options used in this population are approved or recommended options in 2016, this was not true for $18 \%$ of patients who received cisplatin-based chemotherapy [25]. This rate of prescription may be explained by the retrospective nature of our study, the evolution of WHO classification including the recent recognition of NET G3 subgroups and the still debated role of cisplatin-based chemotherapy in aggressive NET.

History of Therapeutic Intervention in pNET
In our population of patients with advanced pNET at diagnosis and with a 5 -year survival rate of $51 \%$, in accordance with previous studies [21], we found that when 5 therapeutic lines had been administered, $50 \%$ of patients had died. In addition, after 3 lines of therapy, $23 \%$ of patients had died and toxic events had already occurred in $8 \%$ of patients. Tumour- or toxicity-related death was the main cause of discontinuation of therapy. The basic conclusion of this result is that not all pNET patients will benefit from all approved or recommended therapeutic options and therefore the ranking of drug administration matters.

During the course of therapeutic interventions, treatment-related deaths and PTRT occurred in 6 and $12 \%$ of

Neuroendocrinology 2017;105:26-34 DOI: $10.1159 / 000446988$ 
Table 4. Baseline tumour and patient characteristics in the groups of patients with and without toxic events

\begin{tabular}{|c|c|c|c|c|c|}
\hline & \multicolumn{2}{|c|}{ Toxic event $(\mathrm{n}=17)$} & \multicolumn{2}{|c|}{ No toxic event $(\mathrm{n}=75)$} & \multirow[t]{2}{*}{$\mathrm{p}$} \\
\hline & $\begin{array}{l}\text { evaluable } \\
\text { patients, } \mathrm{n}\end{array}$ & $\begin{array}{l}\text { results, } \\
\mathrm{n}(\%)\end{array}$ & $\begin{array}{l}\text { evaluable } \\
\text { patients, } \mathrm{n}\end{array}$ & $\begin{array}{l}\text { results, } \\
\mathrm{n}(\%)\end{array}$ & \\
\hline Functioning syndrome & 17 & $4(24)$ & 75 & $27(36)$ & $0.32^{*}$ \\
\hline $\mathrm{Ki} 67>10 \%$ & 13 & $4(31)$ & 56 & $9(16)$ & $0.2^{* *}$ \\
\hline Liver involvement $>70 \%$ & 17 & $2(12)$ & 74 & $8(11)$ & $0.59^{* *}$ \\
\hline Metastatic organs $>1$ & 17 & $2(12)$ & 75 & $12(16)$ & $0.49^{* *}$ \\
\hline Age $>55$ years & 17 & $14(82)$ & 75 & $56(75)$ & $0.03^{*}$ \\
\hline $\mathrm{CKD}>1.5 \mathrm{ULN}$ & 16 & $1(6)$ & 67 & $0(0)$ & $0.19^{* *}$ \\
\hline Bilirubin >1.5 ULN & 14 & $1(7)$ & 61 & $2(3)$ & $0.46^{* *}$ \\
\hline Transaminases $>3$ ULN & 14 & $2(14)$ & 64 & $1(2)$ & $0.08^{* *}$ \\
\hline Haemoglobin < 10 g/dl & 16 & $2(12)$ & 63 & $5(8)$ & $0.43^{* *}$ \\
\hline Comorbidities $^{\mathrm{a}}$ & 17 & $12(70)$ & 75 & $45(60)$ & $0.41^{*}$ \\
\hline First therapeutic line initiated before 2006 & 17 & $14(82)$ & 75 & $31(41)$ & $0.005^{*}$ \\
\hline
\end{tabular}

CKD = Chronic kidney disease; ULN = upper limit of normal. ${ }^{a}$ Comorbidities: tobacco use, hypertension, dyslipidaemia, diabetes mellitus, obesity. Grade is provided according to ${ }^{*} \chi^{2}$ test; ${ }^{* *}$ Fisher's exact test.

cases, respectively. The frequency of toxic events was 8 , 19 and 24\% after 3, 4 and 5 lines, respectively, suggesting cumulative toxicity. Even though these rates are pretty low, efforts should be expended to make this number close to zero. Sparing critical organs from becoming toxicity targets of several lines of treatment is becoming a key objective in patients with advanced pNET due to the increasing number of options available. Renal and cardiac dysfunctions were the most frequent in terms of toxicity. Preliminary recommendations can be derived from our study to decrease the risk of toxic events. Cisplatin-based chemotherapy, a well-known nephrotoxic drug, should be omitted in pNET patients in the absence of protocols as recently evaluated. Indeed, the best level of evidence available suggests no added value of cisplatin-based chemotherapy in NET patients $[22,25,26]$. Of note, several other medical options used in pNET patients have been reported to alter renal function, and their interaction should be closely monitored in the near future. Streptozotocin-based chemotherapy led to renal failure in less than $10 \%$ of patients $[4,7,27]$. Although renal failure is uncommonly described, increased serum creatinine has been reported with sunitinib in $18 \%$ of patients $[14,28$, 29 ] as well as with everolimus in $46 \%$ of cases [30]. Among patients receiving sunitinib in other malignancies, the incidence of creatinine elevation, whatever the grade, ranges from 12.4 to $65.6 \%[28,31,32]$. However, renal function was deteriorated in $57 \%$ of patients with pre-existing renal impairment at the start of therapy with tyrosine ki- nase inhibitors [33]. Laboratory abnormalities including elevated serum creatinine levels, whatever the grade, during everolimus treatment have been reported in 50-77\% of patients in some series $[34,35]$, while grade $3 / 4$ occurred in less than $1 \%$.

In addition, the heart was the second most frequently affected organ. In our study, follow-up was performed in accordance with French recommendations when available [23]. Doxorubicin and 5FU are well-known causes of cardiac toxicity. Although the cumulative dose of $550 \mathrm{mg} /$ $\mathrm{m}^{2}$ of doxorubicin was not exceeded in these patients, intra-patient variability may affect its tolerance as well as when it is given simultaneously with TACE which remains an unstandardised procedure. Several medical options used in pNET patients have been reported to also alter cardiac function, and their interaction should be closely monitored in the near future. Cardiac toxicities may have been underestimated in previous trials since follow-up did not include routine baseline/follow-up electrocardiography and/or echocardiography. In 2 phase III studies with sunitinib in gastrointestinal stromal tumours and metastatic renal cell carcinoma, the frequency of cardiac-related adverse events was reported in 11-13\% of cases including $3 \%$ of grade 3 toxicity $[28,29]$. No change in the LVEF was reported with sunitinib in a trial with patients with gastrointestinal stromal tumour, but $10 \%$ of patients with metastatic renal cell carcinoma experienced a change in LVEF $[31,36]$. No cardiac disorder has been reported in phase III trials with sunitinib or 
everolimus in neuroendocrine tumours $[14,15]$, but case reports on cardiac failure have been published [37]. In addition, treatments at risk of cumulative toxicity should be identified and their use rationalised. Toxic events were found to be cumulative and time related. Only future prospective studies analysing the evolution of patient and tumour characteristics but also treatment sequences in a time-dependent manner will properly answer the key question of the mechanism of the onset of toxic events. Our preliminary analysis suggests that the use of a more aggressive sequence of therapy in pNET patients, with high Ki67 and control of comorbidity, especially in older patients, should be cautiously evaluated.

The limitations of this study include its retrospective design and the period-dependent availability as well as the modality of treatment prescriptions since the start of the study. In line with that comment, our population received mainly systemic chemotherapy or SSA as first-line treatment, a picture that may change in the near future. The frequency of toxicities is underestimated because we only described toxicities which contraindicate other ther- apeutic lines. In addition, only the first residual toxicities were taken into account. Finally, the prescription of cisplatin-based chemotherapy even if reflecting the reallife setting cannot be considered as recommended. The strengths of the study are the multidisciplinary team management with the same senior team from the outset, the use of all available options since 2005 and the low rate of loss to follow-up.

In conclusion, after 3 and 5 therapeutic lines, 23 and $50 \%$ of patients had died and the frequency of toxic events was 8 and 24\%, respectively. Not all patients with pNET will benefit from all approved or recommended therapeutic options. The best treatment sequence should be investigated.

\section{Disclosure Statement}

There is no conflict of interest that could be perceived as prejudicing the impartiality of the research reported. This research did not receive any specific grant from any funding agency in the public, commercial or not-for-profit sector.

\section{References}

1 Korse CM, Taal BG, van Velthuysen M-LF, Visser O: Incidence and survival of neuroendocrine tumours in the Netherlands according to histological grade: experience of two decades of cancer registry. Eur J Cancer 2013; 49:1975-1983.

2 Yao JC, Hassan M, Phan A, Dagohoy C, Leary C, Mares JE, et al: One hundred years after 'carcinoid': epidemiology of and prognostic factors for neuroendocrine tumors in 35,825 cases in the United States. J Clin Oncol 2008; 26:3063-3072.

3 Bajetta E, Zilembo N, Di Bartolomeo M, Di Leo A, Pilotti S, Bochicchio AM, et al: Treatment of metastatic carcinoids and other neuroendocrine tumors with recombinant interferon-alpha-2a. A study by the Italian Trials in Medical Oncology Group. Cancer 1993;72: 3099-3105.

4 Delaunoit T, Ducreux M, Boige V, Dromain C, Sabourin J-C, Duvillard P, et al: The doxorubicin-streptozotocin combination for the treatment of advanced well-differentiated pancreatic endocrine carcinoma; a judicious option? Eur J Cancer 2004;40:515-520.

5 Eriksson B, Skogseid B, Lundqvist G, Wide L, Wilander E, Oberg K: Medical treatment and long-term survival in a prospective study of 84 patients with endocrine pancreatic tumors. Cancer 1990;65:1883-1890.

6 Kouvaraki MA, Ajani JA, Hoff P, Wolff R, Evans DB, Lozano R, et al: Fluorouracil, doxoru-

History of Therapeutic Intervention in pNET bicin, and streptozocin in the treatment of patients with locally advanced and metastatic pancreatic endocrine carcinomas. J Clin Oncol 2004;22:4762-4771.

7 Moertel CG, Lefkopoulo M, Lipsitz S, Hahn RG, Klaassen D: Streptozocin-doxorubicin, streptozocin-fluorouracil or chlorozotocin in the treatment of advanced islet-cell carcinoma. N Engl J Med 1992;326:519-523.

8 Bajetta E, Catena L, Procopio G, De Dosso S, Bichisao E, Ferrari L, et al: Are capecitabine and oxaliplatin (XELOX) suitable treatments for progressing low-grade and high-grade neuroendocrine tumours? Cancer Chemother Pharmacol 2007;59:637-642.

9 Cassier PA, Walter T, Eymard B, Ardisson P, Perol M, Paillet C, et al: Gemcitabine and oxaliplatin combination chemotherapy for metastatic well-differentiated neuroendocrine carcinomas: a single-center experience. Cancer 2009; 115:3392-3399.

10 Strosberg JR, Fine RL, Choi J, Nasir A, Coppola D, Chen D-T, et al: First-line chemotherapy with capecitabine and temozolomide in patients with metastatic pancreatic endocrine carcinomas. Cancer 2011;117:268-275.

11 Imhof A, Brunner P, Marincek N, Briel M, Schindler C, Rasch H, et al: Response, survival, and long-term toxicity after therapy with the radiolabeled somatostatin analogue [90YDOTA]-TOC in metastasized neuroendocrine cancers. J Clin Oncol 2011;29:2416-2423.
12 Kwekkeboom DJ, de Herder WW, Kam BL, van Eijck $\mathrm{CH}$, van Essen $\mathrm{M}$, Kooij PP, et al: Treatment with the radiolabeled somatostatin analog [177 Lu-DOTA 0, Tyr3] octreotate: toxicity, efficacy, and survival. J Clin Oncol 2008;26:2124-2130.

13 Caplin ME, Pavel M, Ćwikła JB, Phan AT, Raderer M, Sedláčková E, et al: Lanreotide in metastatic enteropancreatic neuroendocrine tumors. N Engl J Med 2014;371:224-233.

14 Raymond E, Dahan L, Raoul J-L, Bang Y-J, Borbath I, Lombard-Bohas C, et al: Sunitinib malate for the treatment of pancreatic neuroendocrine tumors. N Engl J Med 2011;364:501-513.

15 Yao JC, Shah MH, Ito T, Bohas CL, Wolin EM, Van Cutsem E, et al: Everolimus for advanced pancreatic neuroendocrine tumors. N Engl J Med 2011;364:514-523.

16 Ducreux M, Dahan L, Smith D, O’Toole D, Lepère C, Dromain C, et al: Bevacizumab combined with 5 -FU/streptozocin in patients with progressive metastatic well-differentiated pancreatic endocrine tumours (BETTER trial) - a phase II non-randomised trial. Eur J Cancer 2014;50:3098-3106.

17 Pavel M, Baudin E, Couvelard A, Krenning E, Öberg K, Steinmüller T, et al: ENETS Consensus Guidelines for the management of patients with liver and other distant metastases from neuroendocrine neoplasms of foregut, midgut, hindgut, and unknown primary. Neuroendocrinology 2012;95:157-176. 
18 Kulke MH, Siu LL, Tepper JE, Fisher G, Jaffe $\mathrm{D}$, Haller DG, et al: Future directions in the treatment of neuroendocrine tumors: consensus report of the National Cancer Institute Neuroendocrine Tumor clinical trials planning meeting. J Clin Oncol 2011;29:934-943.

19 Faiss S, Pape U-F, Böhmig M, Dörffel Y, Mansmann U, Golder W, et al: Prospective, randomized, multicenter trial on the antiproliferative effect of lanreotide, interferon alfa, and their combination for therapy of metastatic neuroendocrine gastroenteropancreatic tumors - the International Lanreotide and Interferon Alfa Study Group. J Clin Oncol 2003; 21:2689-2696.

20 de Baere T, Deschamps F, Tselikas L, Ducreux M, Planchard D, Pearson E, et al: GEP-NETS update: Interventional radiology: role in the treatment of liver metastases from GEPNETs. Eur J Endocrinol 2015;172:R151R166.

21 Baudin E, Planchard D, Scoazec J-Y, Guigay $J$, Dromain C, Hadoux J, et al: Intervention in gastro-enteropancreatic neuroendocrine tumours. Best Pract Res Clin Gastroenterol 2012;26:855-865.

22 Mitry E, Baudin E, Ducreux M, Sabourin JC, Rufié P, Aparicio T, et al: Treatment of poorly differentiated neuroendocrine tumours with etoposide and cisplatin. Br J Cancer 1999;81:1351-1355.

23 Cohen A, Abergel E, Blanchard B, Chauvel C, Habib G, Hagege A, et al: Recommendations of the French Society of Cardiology concerning indications for Doppler echocardiography (in French). Arch Mal Coeur Vaiss 2003; 96:223-263.

24 Cadiot G, Baudin E, Couvelard A, Dromain C, Lepage C, Lombard-Bohas C, Poncet G,
Ruszniewski P, Smith D: Tumeurs neuroendocrines digestives; in Thésaurus National de Cancérologie Digestive, 2014, chapt 11.

25 Pavel M, O'Toole D, Costa F, Capdevila J, Gross D, Kianmanesh R, et al: ENETS Consensus Guidelines Update for the management of distant metastatic disease of intestinal, pancreatic, bronchial neuroendocrine neoplasms (NEN) and NEN of unknown primary site. Neuroendocrinology 2016;103: 172-185.

26 Meyer T, Qian W, Caplin ME, Armstrong G Lao-Sirieix S-H, Hardy R, et al: Capecitabine and streptozocin \pm cisplatin in advanced gastroenteropancreatic neuroendocrine tumours. Eur J Cancer 2014;50:902-911.

27 Dahan L, Bonnetain F, Rougier P, Raoul J-L, Gamelin E, Etienne P-L, et al: Phase III trial of chemotherapy using 5 -fluorouracil and streptozotocin compared with interferon alpha for advanced carcinoid tumors: FNCLCC-FFCD 9710. Endocr Relat Cancer 2009;16:13511361.

28 Demetri GD, Garrett CR, Schöffski P, Shah $\mathrm{MH}$, Verweij J, Leyvraz S, et al: Complete longitudinal analyses of the randomized, placebo-controlled, phase III trial of sunitinib in patients with gastrointestinal stromal tumor following imatinib failure. Clin Cancer Res 2012;18:3170-3179.

29 Motzer RJ, Hutson TE, Tomczak P, Michaelson MD, Bukowski RM, Oudard S, et al: Overall survival and updated results for sunitinib compared with interferon alfa in patients with metastatic renal cell carcinoma. J Clin Oncol 2009;27:3584-3590.

30 Motzer RJ, Escudier B, Oudard S, Hutson TE, Porta C, Bracarda S, et al: Efficacy of everolimus in advanced renal cell carcinoma: a dou- ble-blind, randomised, placebo-controlled phase III trial. Lancet 2008;372:449-456.

31 Motzer RJ, Hutson TE, Tomczak P, Michaelson MD, Bukowski RM, Rixe O, et al: Sunitinib versus interferon alfa in metastatic renal-cell carcinoma. N Engl J Med 2007;356: $115-124$.

32 Zhu X, Stergiopoulos K, Wu S: Risk of hypertension and renal dysfunction with an angiogenesis inhibitor sunitinib: systematic review and meta-analysis. Acta Oncol Stockh Swed 2009;48:9-17.

33 Khan G, Golshayan A, Elson P, Wood L, Garcia J, Bukowski R, et al: Sunitinib and sorafenib in metastatic renal cell carcinoma patients with renal insufficiency. Ann Oncol 2010;21: 1618-1622.

34 Kim KH, Yoon SH, Lee H-J, Kim HS, Shin SJ, Ahn JB, et al: Efficacy and safety of everolimus in Korean patients with metastatic renal cell carcinoma. Cancer Chemother Pharmacol 2013;72:853-860

35 Motzer RJ, Escudier B, Oudard S, Hutson TE, Porta C, Bracarda S, et al: Phase 3 trial of everolimus for metastatic renal cell carcinoma: final results and analysis of prognostic factors. Cancer 2010;116:4256-4265.

36 Demetri GD, van Oosterom AT, Garrett CR, Blackstein ME, Shah MH, Verweij J, et al: Efficacy and safety of sunitinib in patients with advanced gastrointestinal stromal tumour after failure of imatinib: a randomised controlled trial. Lancet 2006;368:1329-1338.

37 Bernard V, Lombard-Bohas C, Taquet M-C, Caroli-Bosc F-X, Ruszniewski P, Niccoli P, et al: Efficacy of everolimus in patients with metastatic insulinoma and refractory hypoglycemia. Eur J Endocrinol 2013;168:665674. 